\title{
LEY FORAL 6/2003, de 14 de febrero, de prevención del consumo de tabaco, de protección del aire respirable y de la promoción de la salud en relación al tabaco
}

\author{
EL PRESIDENTE DEL GOBIERNO DE NAVARRA \\ Hago saber que el Parlamento de Navarra ha aprobado la siguiente \\ LEY FORAL DE PREVENCION DEL CONSUMO DE TABACO, DE PROTECCION DEL AIRE RES-
} PIRABLE Y DE LA PROMOCION DE LA SALUD EN RELACION AL TABACO

\section{EXPOSICION DE MOTIVOS}

En las sociedades modernas el tabaquismo es uno de los factores causales más relevantes como problema de salud pública, siendo además la causa prevenible más importante de morbi-mortalidad con la particularidad de que induce una dependencia, cuyo tratamiento requiere en muchos casos de intervenciones similares a las que se utilizan para otras sustancias adictivas.

Su alta difusión y presencia provoca un elevado coste social, sanitario, económico y de sufrimiento innecesario, y dado que la salud es un valor de primer orden cuya exigencia viene demandada tanto por los ciudadanos individual como colectivamente, a través de los poderes públicos, se convierte en una responsabilidad de todos la adopción de medidas protectoras y promotoras de salud.

Considerando que la venta, publicidad y promoción de los productos de tabaco, con las restricciones existentes, no impide que ésta llegue a los jóvenes y provoca un aumento de la demanda de cigarrillos entre los adolescentes, se plantea la necesidad de establecer las condiciones necesarias para que el uso en el consumo de tabaco no se difunda a nuestra población más vulnerable.

Por otro lado, existen datos científicos sobre los riesgos para la salud en la población no fumadora vinculados a la contaminación ambiental por humo de tabaco. Por ello parece adecuado arbitrar medidas que preserven el derecho a la protección de la salud de estos ciudadanos y puedan desarrollar su actividad cotidiana sin riesgos no deseados y sin discriminación.

Teniendo en cuenta que en caso de conflicto prevalecerá siempre el derecho a la salud de los no fumadores sobre el derecho de los fumadores a consumir labores de tabaco en todos aquellos lugares o circunstancias en que pueda afectarse el derecho a la salud de los primeros, que la protección a la población menor de edad es, no sólo legítima, sino necesaria desde cualquier mandato legal o ético; que es necesario abordar el tratamiento del tabaquismo desde los servicios sanitarios como cualquier otro problema de salud y que la información y la educación deben ser acorde a las investigaciones sobre el tema, se justifica la promulgación de las medidas que se desarrollan en los capítulos siguientes.

Dado además que las actuales disposiciones legales vigentes presentan carencias importantes, la Unión Europea orienta todas sus directivas en materia de tabaco con el objetivo del "máximo de salud posible". Desde este referente queremos enmarcar la Ley Foral que aquí se presenta. Es por tanto, una Ley Foral positiva, no limitadora de derechos, sino protectora y promotora de salud. Ello cobra mayor legitimidad desde la aprobación del Plan Foral de Acción sobre el Tabaco por el parlamento de Navarra el 27 de abril de 2001, cuyo reflejo es esta normativa legal.

II

El artículo 43 de la Constitución Española reconoce el derecho a la protección de la salud y establece que es a los poderes públicos a quienes compete organizar y tutelar la salud pública a través de medidas preventivas, fomentando la educación sanitaria.

El artículo 25.2 de la Ley 14/1986, General de Sanidad, establece que deban establecerse prohibiciones y requerimientos mínimos para el uso y tráfico de los bienes cuando supongan un riesgo o daño para la salud. Al amparo del mismo y del artículo 3.2 de la Ley 26/1984, de 19 de julio, General para la defensa de los consumidores y usuarios, se dicta el Real Decreto 192/1988, de 4 de marzo, sobre lim- 
itaciones en la venta y uso del tabaco para protección de la salud de la población, que en su artículo 1.으 declara al tabaco sustancia nociva para la salud de la persona y en consecuencia en caso de conflicto prevalecerá siempre el derecho a la salud de los no fumadores sobre el derecho de los fumadores a consumir labores de tabaco en todos aquellos lugares o circunstancias en que pueda afectarse el derecho a la salud de los primeros.

Del mismo año es la Ley 34/1988, de 11 de noviembre, General de Publicidad, la cual en referencia especifica al tabaco prohíbe la publicidad por medio de la televisión y en aquellos lugares en los que este prohibida su venta o consumo. Asimismo, remite a regulación reglamentaria el establecimiento de limitaciones en orden a la protección de la salud y seguridad de las personas.

En virtud de las mismas diversas disposiciones han venido a establecer limitaciones y restricciones, y en algunos casos a fin de incorporar al ordenamiento español diversas directivas europeas, entre las que cabe citar la Directiva 89/552/CEE. Más recientemente la Directiva 98/43/CE ha constituido un intento de abordar una regulación homogénea en materia de restricciones a la publicidad y patrocinio de los productos del tabaco; iniciativa fallida por cuanto fue anulada por sentencia del Tribunal de J usticia Europeo de 5 de octubre de 2000, si bien ha dado lugar a una nueva Directiva en preparación en esta materia, mediante la que se incorporan las consideraciones y matices realizados en la citada sentencia.

Por lo que respecta a la Comunidad Foral de Navarra, la presente norma se dicta en ejercicio de las competencias atribuidas a la Comunidad Foral de Navarra en los artículos 44.18 y 25, 53.1 y 56.1 .d) de la Ley Orgánica 13/1982, de 10 de agosto, de Reintegración y Amejoramiento del Régimen Foral de Navarra.

Todos estos títulos competenciales, a excepción del enunciado en el apartado d), comprenden la potestad legislativa.

III

Mediante Orden Foral 259/1999, de 11 de octubre, el Consejero de Salud creó el Comité de Expertos para la elaboración de un Plan Foral de Tabaco compuesto por un equipo multidisciplinar de profesionales procedente de diferentes ámbitos, y le encomendó como tarea principal la elaboración de un Plan Foral de Tabaco a desarrollar en el ámbito de Navarra que contemple la totalidad de las intervenciones que sea factible realizar desde los distintos poderes públicos con el concurso de todos los agentes de la Comunidad.

Dando cumplimento al encargo, se confecciono y aprobó de común acuerdo entre todos los componentes del Comité un Plan Foral de Acción sobre el Tabaco, que fue elevado al Gobierno de Navarra con fecha 15 de mayo de 2000 para su aprobación inicial, al objeto de abrir un plazo para el que el Departamento de Salud realizara una difusión del mismo entre los diferentes Departamentos de la Administración de la Comunidad Foral así como entre las instituciones y entidades de la Comunidad afectadas por el mismo, al objeto de realizar la aportaciones y sugerencias que estimaran oportunas. Realizada la misma y estudiadas las alegaciones presentadas se confeccionó un nuevo Plan que fue aprobado por el Gobierno de Navarra con fecha 18 de septiembre del mismo año, quien determinó su remisión al Parlamento de Navarra para su aprobación.

Visto el Plan en la Comisión de Sanidad del Parlamento de Navarra en sesión celebrada el día 27 de abril del 2001 se aprobó el Plan con la incorporación de unas pocas propuestas que han quedado finalmente incorporadas al mismo.

Con el fin de articular las previsiones del referido Plan e iniciar su ejecución mediante Decreto Foral 127/2001, de 28 de mayo, se establecieron los órganos de dirección y coordinación del Plan Foral de Acción sobre el Tabaco, posibilitando la adopción de las medidas tendentes a la puesta en marcha del Plan.

El Plan Foral de Acción sobre el Tabaco contempla no sólo una aproximación al problema del tabaquismo y a la situación y respuestas en Navarra sino un plan de actuación para el periodo 20002005. Dicho Plan de actuación contempla además de aspectos generales tales como objetivos, principios de actuación, medidas estratégicas recursos, sistemas de información y evaluación y un cronograma del proceso de aprobación, la concreción de unos programas específicos, a saber el de prevención del inicio, el de ayuda a dejar de fumar y el de espacios sin humo, que constituyen los tres grandes ejes en torno a los que gira el Plan.

En definitiva, del mismo derivan medidas y actuaciones muy diversas para cometer en su conjunto una aproximación a un problema de salud con connotaciones muy variadas en aspectos socioculturales y ambientales, a través de los cuales no se trata de arremeter contra el fumador sino contra todos aquellos aspectos que contribuyen al aumento del numero de fumadores y a marcar pautas que permitan una 
convivencia basada en el respeto tanto al fumador como a los terceros no fumadores que se ven expuestos a las consecuencias del humo.

Todo ese conjunto de actuaciones tienen ejecuciones muy diversas pero se constata la necesidad de una Ley Foral que enmarque todo ese conjunto de actuaciones y que sirva de pauta para acometerlas de un modo coordinado por parte de todas la instancias implicadas y que sirvan de base consensuada para las actuaciones públicas al respecto.

\section{IV}

La presente Ley Foral se compone de un Título preliminar y tres Títulos diferenciados que llevan por título: I. Actuaciones de Prevención y Promoción, II. Actuaciones de Protección y III. Régimen Sancionador.

Dicha separación viene a diferenciar claramente por una parte el conjunto de actuaciones que se enmarcan en la denominación de actividades de promoción, de aquellas otras que se califican como de protección. Con arreglo a las definiciones doctrinales contenidas en el artículo 2 de la presente Ley Foral.

El Título Preliminar agrupa un conjunto de disposiciones generales tales como el objeto de la Ley Foral, los principios rectores y unas definiciones en torno a conceptos sobre los que gira toda la ley foral. Dentro de los principios rectores destaca la consideración del consumo de tabaco como un problema de salud y la prioridad de las intervenciones cuyo objetivo sea la prevención del consumo de tabaco o de los efectos que de él puedan derivarse y la búsqueda del consenso social para la adopción de las medidas protectoras, especialmente las relativas al consumo en espacio cerrados.

El título I dedicado a las actuaciones de prevención y promoción, esto es dedicado tanto al entramado dinámico de estrategias y actuaciones dirigidas a modificar los factores personales, sociales y culturales que pueden ser favorecedores del consumo de tabaco, como de medias informativas, de educación para la saludo, y de fomento e incentivación de actuaciones tendentes a la mejora de la salud. A lo largo de sus 4 capítulos, aborda unos objetivos generales (Cap. I) en orden a la promoción, desarrollo, fomento, coordinación, control y evaluación de los programas y actuaciones, así como las actividades de promoción (Cap. II) esto es de información, promoción y educación para la salud e investigación, un Capítulo el III dedicado a la asistencia sanitaria, esto es a las acciones dirigidas al tratamiento de la dependencia del tabaco y un Capitulo IV en el que se abordan las competencias de las Administraciones Públicas, dando un especial papel a los Ayuntamientos en sus respectivos términos municipales y reservando competencias de planificación y de actuación más especificas para toda la Comunidad al Gobierno de Navarra y al Departamento de Salud, previendo en este apartado tanto la existencia de una estructura que acometa las distintas fases del Plan Foral de Acción sobre el Tabaco, y previendo una financiación especifica para poder acometer todas la actuaciones contenidas en la Ley Foral.

El Título II se dedica a las actuaciones de protección, esto es al conjunto de normas y actuaciones limitadoras cuyo objeto es la defensa del derecho a la salud de las personas y la protección de la población ante la publicidad, promoción y patrocinio de los productos del tabaco. Por su contenido tiene un Capítulo I dedicado a las limitaciones de la comunicación comercial y patrocinio del tabaco, un Capitulo II dedicado a su venta y un Capítulo III en el que se establece el régimen de protección del aire respirable de la contaminación del humo del tabaco.

Finalmente el Título III recoge el régimen Sancionador, estableciendo una tipificación de infracciones administrativas que podrán ser objeto de sanción previa instrucción del correspondientes expediente con arreglo al procedimiento que le sea aplicable.

Termina con un conjunto de disposiciones adicionales, transitorias, derogatorias y finales.

$$
\text { TITULO PRELIMINAR }
$$

Disposiciones generales

Artículo 1.0 Objeto de la Ley Foral.

La presente Ley Foral tiene por objeto la adopción de medidas reguladoras de actuaciones dirigidas a establecer un adecuado nivel de protección de la salud frente a los riesgos derivados del consumo de tabaco, a la prevención del inicio de su consumo y a la promoción de hábitos saludables para la mejora de la calidad de vida de la ciudadanía.

\section{Artículo 2.o Definiciones.}

En el marco de la presente Ley Foral, se entiende por: 
a) Prevención: Entramado dinámico de estrategias y actuaciones dirigidas a modificar los factores personales, sociales y culturales que pudieran ser favorecedores del consumo de tabaco.

b) Protección: Conjunto de normas y actuaciones para la eliminación o disminución de los riesgos para la salud de la ciudadanía derivados del consumo de tabaco, así como la protección ciudadana y la protección del aire respirable de la población ante los medios de promoción de dicho consumo.

c) Promoción: Conjunto de medidas de sensibilización social, de educación para la salud, movilización y reorientación de servicios y recursos para actuaciones comprometidas con el fomento de hábitos saludables para la mejora de la salud y la calidad de vida de la ciudadanía.

d) Tabaco: Todos los productos destinados a ser fumados, inhalados, chupados o masticados, siempre que estén constituidos, aunque sólo sean en parte, por tabaco.

Artículo 3.o Principios rectores.

Las actuaciones que desarrollen las Administraciones Públicas de Navarra en relación con el tabaco se ajustarán a los siguientes principios rectores:

a) Proteger la calidad del aire respirable libre de contaminantes del humo del tabaco.

b) La consideración del consumo de tabaco como un riesgo para la salud individual y colectiva.

c) La promoción de hábitos saludables.

d) La prioridad de las intervenciones cuyo objetivo sea la prevención del consumo de tabaco o de los efectos que de él puedan derivarse.

e) La integración de las actuaciones en relación al tabaco en los sistemas educativo, sanitario y social de la Comunidad Foral.

f) Búsqueda del consenso social para la adopción de las medidas protectoras para satisfacer el derecho de los no fumadores al disfrute de un aire libre de humo de tabaco, en especial los menores de edad y personas enfermas en relación al consumo en espacios cerrados.

g) Considerar el consumo de tabaco como un derecho del ciudadano que se ejercita en el ámbito privado.

\section{TITULO I}

Actuaciones de prevención y promoción

\section{CAPITULO I}

Objetivos generales

Artículo 4.ㅇ Objetivos generales.

Las Administraciones públicas de Navarra dirigirán las actuaciones de promoción, desarrollo, fomento, coordinación y control de los programas que desarrollen en el ejercicio de sus respectivas competencias a:

a) Informar a la población sobre las sustancias adictivas y nocivas que contienen los productos del tabaco, sus efectos y los riesgos y consecuencias para la salud derivadas del uso de las mismas.

b) Educar para la salud, potenciando hábitos saludables frente a las actitudes favorecedoras del consumo de tabaco. co.

c) Intervenir sobre las condiciones socioculturales y ambientales que inciden en el consumo de taba-

\section{CAPITULO II}

Objetivos específicos

Artículo 5.9 Información.

El Gobierno de Navarra realizará las siguientes actuaciones de carácter informativo para la prevención del consumo de tabaco:

a) Promoverá el desarrollo de campañas informativas sobre los efectos del consumo de tabaco, con el objetivo de modificar actitudes y hábitos relacionados con el mismo, y facilitará el acceso de la población a la información sobre los recursos de intervención existentes. 
b) Mantendrá los sistemas apropiados de información y de vigilancia epidemiológica para la detección de tendencias, hábitos, circunstancias en las que se producen y consecuencias del tabaco, a fin de facilitar una adecuada planificación de la prevención.

c) Facilitará información actualizada a los usuarios y profesionales de las áreas sanitaria, educativa y laboral, así como de los sectores comerciales, sobre los efectos del tabaco.

Artículo 6.9 Promoción y educación para la salud.

El Gobierno de Navarra realizará las siguientes actuaciones en materia de educación para la salud y prevención del consumo de tabaco:

1. Impulsará, en colaboración con los organismos competentes la prevención del consumo de tabaco en el marco de la educación y promoción de la salud en los centros escolares.

A tal efecto el Departamento de Educación del Gobierno de Navarra podrá incorporar al currículo escolar en la Educación Obligatoria y Posobligatoria la asignatura de educación para la salud que incluya diferentes materias ligadas a la salud biopsicosocial.

Los contenidos y programas se establecerán conjuntamente con el Departamento de Salud a través del Convenio correspondiente.

2. Colaborará con las entidades locales para la elaboración de planes municipales de prevención del consumo de tabaco, desde la perspectiva de la promoción de la salud.

3. Impulsará las iniciativas de otras entidades o colectivos sociales en materia de educación para la salud y prevención del consumo de tabaco.

4. Impulsará, en colaboración con los organismos competentes, la formación de los estudiantes de ciencias de la salud, magisterio, prevención de riegos laborales y en general a todos los profesionales que trabajan con jóvenes, en temas de prevención y el tratamiento del consumo de tabaco.

Artículo 7.9 Investigación.

El Gobierno de Navarra promoverá la realización de los estudios y proyectos de investigación que considere necesarios sobre el fenómeno de la dependencia tabáquica.

El Gobierno de Navarra, a través del Instituto de Salud Pública de Navarra, llevará a cabo las investigaciones que estime oportunas sobre el contenido de los productos de tabaco vendidos en Navarra, especialmente por los componentes de nicotina y alquitrán y otras sustancias con potencial adictivo y, particularmente, sobre su incidencia en la población más joven.

\section{CAPITULO III}

Atención sanitaria

Artículo 8. Objetivos generales.

Las acciones que se desarrollen en la Comunidad Foral de Navarra dirigidas al tratamiento de la dependencia del tabaco tendrán por finalidad garantizar la atención en los servicios sanitarios a las personas que soliciten ayuda para dejar de fumar.

Artículo 9.9 Criterios de actuación.

1. Los servicios que desarrollen programas de abandono del tabaco actuarán según los siguientes criterios:

a) La atención a los problemas de salud derivados del tabaco se realizará preferentemente en el ámbito comunitario, y con criterios de equidad en la distribución territorial de los programas.

b) La atención a través del Programa de Ayuda a Dejar de Fumar quedará garantizada en cualesquiera de los niveles de atención de la red sanitaria pública, y comprenderá el acceso a terapia farmacológica que haya mostrado su eficacia, en los términos en que se establezca reglamentariamente.

c) La oferta deberá ser accesible, profesionalizada e interdisciplinar, estará basada en intervenciones comportamentales y farmacológicas y prestará especial atención a los colectivos más vulnerables, en particular a la adolescencia.

d) Todas las estructuras sanitarias y el personal sanitario de todos los niveles de atención implicados en el Programa Ayuda a dejar de fumar, se adaptarán y formarán adecuadamente para poder alcanzar correctamente el objetivo de esta Ley Foral. 
Artículo 10. Organización de la atención. ción:

El desarrollo de programas de apoyo al abandono del tabaco se conformará por dos niveles de aten-

A._Primer nivel, formado por:

a) Equipos de atención primaria de salud.

b) Salud laboral y servicios de prevención de riesgos laborales.

B._Segundo nivel, formado por:

a) Centros de atención a la mujer.

b) Centros de salud mental.

c) Atención especializada y otros centros y servicios específicos en nuestra Comunidad.

Artículo 11. Ambito penitenciario.

El Gobierno de Navarra, en colaboración con el organismo competente en materia de instituciones penitenciarias y los servicios sanitarios de los centros penitenciarios ubicados en la Comunidad Foral, podrá establecer la puesta en marcha de programas de apoyo para el abandono del hábito del tabaco.

Artículo 12. Ambito laboral.

El Gobierno de Navarra promoverá la consideración del consumo de tabaco en la realización de las evaluaciones de riesgos en el puesto de trabajo y la vigilancia de la salud de los trabajadores.

\section{CAPITULO IV}

Competencias de las administraciones públicas

Artículo 13. Competencias del Gobierno de Navarra.

Sin perjuicio de las demás competencias que el ordenamiento vigente le atribuye, corresponde al Gobierno de Navarra:

a) La planificación general y la evaluación de las necesidades, demandas y recursos relacionados con las materias objeto de la presente Ley Foral.

b) La coordinación y ordenación de las funciones, actuaciones y servicios que en la materia que aborda la presente Ley Foral tengan que desarrollar las distintas Administraciones e instituciones públicas, privadas o de iniciativa social sin ánimo de lucro de la Comunidad Foral de Navarra.

c) El ejercicio de la potestad inspectora y sancionadora en los términos previstos en esta Ley Foral.

d) La promoción de programas interdisciplinares de formación dirigidos al personal sanitario y educativo, así como a cualquier otro cuya actividad profesional se relacione directa o indirectamente con el consumo de tabaco. Para ello, además de sus propios recursos, contarán con el apoyo de otras Administraciones públicas y de las iniciativas sociales o asociaciones que articulen proyectos de formación.

e) La adopción, en colaboración con otras Administraciones públicas, de todas aquellas medidas que sean precisas para asegurar el buen desarrollo de esta Ley Foral.

Artículo 14. Competencias de las entidades locales.

Sin perjuicio de las demás competencias que el ordenamiento vigente les atribuye, corresponde a las entidades locales de Navarra:

a) La dirección de aquellos programas propios relacionados con el consumo de tabaco que se desarrollen en su ámbito territorial y la coordinación con otros programas.

b) El ejercicio de la potestad inspectora y sancionadora en los términos previstos en esta Ley Foral.

c) La colaboración con los sistemas educativo y sanitario en materia de educación para la salud.

Artículo 15. Plan Foral de Acción sobre el Tabaco.

El Gobierno de Navarra establecerá la organización y funcionamiento de los órganos de dirección y coordinación del Plan Foral de Acción sobre el Tabaco, conforme a las previsiones del mismo y con sujeción a lo previsto en la presente Ley Foral y disposiciones dictadas para su desarrollo.

Artículo 16. Financiación.

El Gobierno de Navarra incluirá cada año en los presupuestos de la Comunidad Foral la dotación suficiente para el desarrollo de las acciones previstas en esta Ley Foral. 


\section{TITULO ॥}

Actuaciones de protección

CAPITULO I

Limitaciones a la comunicación comercial y promoción del tabaco

Artículo 17. Condiciones de la comunicación comercial, promoción y patrocinio del tabaco.

1. Sin perjuicio de lo establecido en la legislación estatal en el ámbito de su competencia, queda prohibida en la Comunidad Foral de Navarra la promoción comercial, tanto directa como indirecta, de los productos del tabaco, a excepción de las presentaciones de estos productos en los puntos de venta autorizados.

La publicidad y cualquier otra forma de comunicación comercial a través de los medios de comunicación social de los productos del tabaco se someterá a la legislación estatal en la materia.

No podrán distribuirse ni venderse en Navarra publicaciones impresas y revistas que vayan dirigidas a la población juvenil o infantil y lleven insertada publicidad directa 0 indirecta del consumo de tabaco.

2. No podrá realizarse en la Comunidad Foral de Navarra patrocinio de actividades deportivas, culturales o de cualquier otro tipo por parte de personas físicas o jurídicas cuya actividad principal o conocida sea la fabricación o la venta de tabaco, si ello lleva implícita la aparición de dicho patrocinio o la difusión de marcas, símbolos o imágenes relacionados con el tabaco.

No podrá insertarse publicidad o cualquier otra forma de comunicación comercial en las marquesinas de los servicios de transporte público ni en las vallas de las vías públicas.

3. Las prohibiciones contenidas en este artículo se extienden a todo tipo de comunicación comercial, directa o indirecta, incluyendo la comunicación comercial de objetos o productos que, por su denominación, grafismo, modo de presentación o cualquier otra causa, pueda suponer una comunicación comercial encubierta de tabaco.

4. A efectos de lo previsto en la presente Ley Foral se entiende por:

Publicidad: toda forma de comunicación realizada por una persona física o jurídica, pública o priva$\mathrm{da}$, en el ejercicio de una actividad comercial, artesanal o profesional, con el fin de promover de manera directa o indirecta cualquier producto del tabaco.

Puntos de venta de tabaco: cualquier lugar en el que se venda productos del tabaco.

Patrocinio: cualquier tipo de contribución, pública o privada, a un acontecimiento, a una actividad o a un individuo cuyo objetivo o efecto directo o indirecto sea la promoción de un producto del tabaco.

Artículo 18. Promoción del consumo de tabaco.

1. Quedan prohibidas en la Comunidad Foral de Navarra las actividades de promoción de tabaco en ferias, certámenes, exposiciones, muestras y actividades similares, con independencia del lugar donde se realicen.

2. En las visitas a centros de producción, elaboración y distribución de tabaco no podrán ofrecerse los productos a los menores de 18 años.

\section{CAPITULO ॥}

Limitaciones a la venta

Artículo 19. Limitaciones a la venta.

1. Queda prohibida en el territorio de la Comunidad Foral de Navarra la venta, suministro o dispensación, gratuita o no, por cualquier medio, de tabaco, sus productos, labores o imitaciones a personas menores de 18 años.

En todos los establecimientos donde se venda o suministre tabaco o sus labores, deberá colocarse, de forma visible al público y en las inmediaciones de estos productos, carteles que adviertan de la prohibición establecida.

2. La venta de tabaco podrá realizarse de forma manual en los establecimientos autorizados al efecto o mediante el empleo de máquinas automáticas. Cuando la venta se efectúe a través de máquina automática, esta estará bajo la responsabilidad del titular del establecimiento y bajo su vigilancia o la de sus empleados. En la superficie frontal de estas máquinas, en lugar visible, se hará constar la prohibición que tienen los menores de 18 años de adquirir tabaco. 
3. Se prohíbe la venta y suministro de tabaco en los siguientes lugares:

a) Los centros y dependencias de las Instituciones de Navarra y de las Administraciones Públicas ubicadas en Navarra, así como sus Organismos Autónomos.

b) Los centros sanitarios, sociosanitarios y de servicios sociales, y sus dependencias.

c) Los centros docentes.

d) Las instalaciones susceptibles de albergar prácticas deportivas, excepto en sus cafeterías o bares.

e) Los centros de atención o esparcimiento de menores.

f) La vía pública.

Artículo 20. Máquinas expendedoras.

El Gobierno de Navarra promoverá la adopción de medidas en orden a incentivar la progresiva introducción de sistemas tendentes a controlar la no accesibilidad de los menores a la compra de tabaco en las máquinas expendedoras.

\section{CAPITULO III}

Protección del aire respirable de la contaminación del humo del tabaco

Artículo 21. Limitaciones al consumo.

En cualquier espacio público o colectivo donde hayan de convivir fumadores y no fumadores, prevalece el derecho del no fumador a disponer de un aire respirable libre de contaminación por el humo del tabaco. El pleno derecho a fumar tiene carácter individual en el ámbito de la privacidad y queda regulado en el ámbito social debido al perjuicio que puede derivarse a terceros.

2. Está prohibido fumar en:

a) Los centros, servicios o establecimientos sanitarios y sociosanitarios.

b) Los centros de atención social destinados a menores de 18 años, a mayores y a personas con discapacidad.

c) Los espacios cerrados de esparcimiento y ocio para uso infantil y juvenil.

d) Los centros docentes no universitarios.

e) Los centros universitarios o de enseñanza dirigida a mayores de edad.

f) Los centros e instalaciones deportivas cerrados. ilares.

g) Las salas de uso público general destinadas a lectura, conferencias, exposiciones, museos o sim-

h) Las salas de teatro, cine y otros espectáculos públicos en locales cerrados.

i) Las oficinas y dependencias laborales de las Administraciones públicas, y todas las destinadas a la atención directa al público.

j) Cualquier área laboral donde trabajen mujeres embarazadas.

k) Los lugares donde exista mayor riesgo para la salud del trabajador por combinar la nocividad del tabaco con el perjuicio ocasionado por el contaminante industrial.

I) Los espacios laborales cerrados compartidos por dos o más personas.

m) Los centros comerciales cerrados.

n) Las salas de espera en estaciones de autobuses, trenes o aeropuertos.

ñ) Cualquier medio de transporte público colectivo, urbano e interurbano, incluidos los vehículos de transporte escolar y todos los destinados total o parcialmente al transporte de menores de 18 años o de enfermos.

o) Los locales donde se elaboren, transformen, manipulen, preparen o vendan alimentos, excepto aquellos que estén destinados al consumo de los mismos, donde se diferenciarán las zonas destinadas a fumadores y no fumadores, en los términos que se establezcan reglamentariamente.

p) Los ascensores y otros recintos pequeños de escasa ventilación, destinados al uso de personas, tanto en instalaciones públicas como privadas.

q) Los lugares similares a los mencionados en este apartado que se determinen reglamentariamente. 
3. En los centros contemplados en los apartados a), b), e), f), h), i), j), I), m), n) y o) se dispondrá de espacios expresamente habilitados para fumar, separados de los espacios destinados para los no fumadores. Estos espacios deben garantizar en los centros contemplados en los apartados a) y e) que existan dos zonas separadas e independientes, una destinada para los usuarios de los servicios y otra destinada para el personal del centro, servicio o establecimiento; de no poder garantizarse dicha separación, estará prohibido fumar en todo el centro.

4. Sin perjuicio de que transitoriamente se puedan adecuar delimitaciones provisionales, en los casos previstos en el apartado anterior, las zonas que se deseen habilitar para fumadores deberán reunir los siguientes requisitos:

a) Estar nítidamente separadas y contar con sistemas de ventilación adecuados.

b) No estar ubicadas en zonas de paso obligado para no fumadores o salas de espera.

c) Encontrarse su ubicación claramente señalizada.

En el caso de que no pudieran cumplirse los anteriores requisitos, se entenderá que todo el local deberá ser libre de humo.

5. No se entenderán comprendidos en los centros relacionados en el apartado 2 aquellas dependencias destinadas a la hostelería que se hallen ubicadas en los mismos, siempre y cuando en las mismas se cumplan los requisitos establecidos en el apartado 3. En otro caso se entenderán que deberán igualmente ser libres de humo.

6. En todos los establecimientos donde esté prohibido fumar existirán a disposición de los interesados hojas de reclamación.

Artículo 22. Señalización.

En todos los lugares, locales o zonas aludidas en el artículo anterior estará visible y convenientemente señalizada la prohibición de fumar.

Artículo 23. Espacios sin humo de tabaco.

Tiene la consideración de espacio sin humo de tabaco cualquier sala, recinto, centro o establecimiento público o privado, con concurrencia de personas, del que se haya eliminado la comunicación comercial, el consumo y la venta de productos de tabaco, permitiendo fumar únicamente en los lugares designados al efecto si los hubiere.

El titular de un centro o establecimiento abierto al público, cualquiera que sea su destino, podrá establecer prohibiciones para fumar en el mismo, previa señalización adecuada para conocimiento de los usuarios.

Artículo 24. Centros o actividades sin humo de tabaco.

1. El Departamento de Salud podrá declarar un centro, establecimiento o actividad como "centro/actividad sin humo de tabaco" cuando esté prohibida la comunicación comercial, venta y consumo de tabaco en la totalidad del espacio que ocupa.

Dicha declaración quedará acreditada al exterior en la forma en que reglamentariamente se determine.

2. El Departamento de Salud promoverá el establecimiento de incentivos para que los titulares o responsables de centros, servicios y establecimientos soliciten dicha declaración.

TITULO III

Régimen sancionador

CAPITULO I

Disposiciones generales

Artículo 25. Organos competentes.

Son competentes para la imposición de las sanciones que, en su caso, procedan por las infracciones tipificadas en la presente Ley Foral las autoridades sanitarias con potestad sancionadora contempladas en la Ley Foral 10/1990, de 23 de noviembre, de Salud.

Corresponde a la autoridad sanitaria prevista en la Ley Foral 10/1990, de Salud: Gobierno de Navarra, Consejero y Director General del Departamento de Salud y a los Alcaldes en sus respectivos 
ámbitos, la implantación y cumplimiento de la Ley Foral, así como la evaluación, control, inspecciones y, en su caso, sanción de las infracciones comprobadas.

La Administración de la Comunidad Foral podrá actuar en sustitución de los Ayuntamientos en los supuestos y con los requisitos previstos en la legislación de régimen local.

Artículo 26. Sujetos responsables.

Son sujetos responsables de la infracción las personas físicas o jurídicas que incurran en las acciones u omisiones tipificadas en esta Ley Foral.

Los titulares de entidades, establecimientos, empresas o servicios y las personas que estén bajo su dependencia, serán responsables solidarios cuando, por acción u omisión, permitan o toleren la comisión de dichas infracciones por parte de sus empleados o del público en general.

Artículo 27. Inspecciones.

1. Las inspecciones podrán ser realizadas por funcionarios de la Administración debidamente acreditados, que tendrán, en el ejercicio de sus funciones, el carácter de agentes de la autoridad.

2. Los titulares de las entidades, establecimientos, empresas o servicios, así como sus representantes, están obligados a permitir el acceso de los funcionarios que desarrollen las funciones de inspección, cuando ejerzan tales funciones, debidamente acreditados al efecto para efectuar las inspecciones, estando igualmente obligados a prestarles la colaboración necesaria para el desarrollo de las mismas.

3. El resultado de la inspección deberá consignarse en un acta.

4. En el ejercicio de sus funciones, los agentes de inspección podrán recabar el auxilio de la autoridad competente.

Artículo 28. Procedimiento.

Las infracciones en materia de prevención, promoción y protección de la salud en relación al tabaco, serán objeto de las sanciones administrativas correspondientes, previa instrucción del oportuno expediente sancionador.

Artículo 29. Prescripción de las infracciones y sanciones.

1. Las infracciones a que se refiere la presente Ley Foral calificadas como leves prescribirán a los seis meses; las graves, al año, y las muy graves, a los dos años. El plazo de prescripción empezará a contar desde el día en que se haya cometido la infracción.

2. Asimismo, las sanciones calificadas como leves prescribirán a los seis meses; las graves, al año, y las muy graves, a los dos años. El plazo de prescripción de las sanciones empezará a contar desde el día siguiente a aquel en que adquiera firmeza la resolución imponiendo la sanción.

\section{CAPITULO ॥}

Infracciones

Artículo 30. Infracciones.

1. Constituyen infracciones administrativas en materia de prevención, promoción y protección de la salud en relación al tabaco, las acciones y omisiones tipificadas y sancionadas en la presente Ley Foral, sin perjuicio de las responsabilidades civiles o penales que puedan concurrir.

2. Las infracciones se clasifican en leves, graves y muy graves.

2.1. Constituyen infracciones leves:

a) El incumplimiento por parte de los responsables de los centros o de la actividad, de la prohibición de fumar, contenida en el artículo 21.

b) El incumplimiento de las obligaciones de carácter formal o de señalización externa establecidas en la presente Ley Foral.

c) El retraso en el cumplimiento de las obligaciones de información, comunicación o comparecencia a requerimiento de la autoridad competente.

d) Cualquier otro incumplimiento de lo previsto en la presente Ley Foral que no se tipifique como infracción grave o muy grave.

2.2. Constituyen infracciones graves:

a) La reincidencia en la comisión de infracciones leves. 
b) El incumplimiento de lo dispuesto en los artículos 17 y 18 sobre limitaciones a la comunicación comercial y promoción del tabaco, así como la contravención de lo dispuesto sobre venta y suministro de tabaco en el artículo 19.

c) La negativa a facilitar información o prestar colaboración a los servicios de inspección y el falseamiento de la información facilitada.

d) El incumplimiento de los requisitos, condiciones, obligaciones o prohibiciones que determina la presente Ley Foral si, de acuerdo con los criterios fijados en este artículo, debe calificarse como infracción grave y no ha sido calificada como muy grave.

2.3. Constituyen infracciones muy graves:

a) La reincidencia en la comisión de infracciones graves.

b) La coacción, amenaza, represalia, desacato o cualquier otra forma de presión que se ejerza sobre las autoridades sanitarias o sus agentes en actividades de control e inspección.

c) Las infracciones que produzcan un grave perjuicio para la salud pública.

d) El incumplimiento de los requisitos, condiciones, obligaciones o prohibiciones que determina la presente Ley Foral si, de acuerdo con los criterios fijados en este artículo, debe calificarse como infracción muy grave, en especial si producen alteración o riesgo sanitario de trascendencia directa para la población.

\section{CAPITULO III}

\section{Sanciones}

Artículo 31. Graduación.

1. Las infracciones señaladas en la presente Ley Foral serán sancionadas aplicando una graduación mínima y máxima a cada tipo de infracción, en función de criterios de riesgo para la salud, grado de incidencia en la sociedad de la alteración producida, el perjuicio causado, número de personas afectadas, duración de los riesgos generados, cuantía del beneficio ilícitamente obtenido, grado de intencionalidad e incumplimiento de las advertencias previas, de acuerdo a lo dispuesto en el artículo 29 de la Ley Foral 10/1990, de Salud y disposiciones concurrentes.

2. En los casos de especial gravedad, infracción continuada o trascendencia grave para la salud pública, el Gobierno de Navarra podrá acordar la suspensión temporal de la actividad o el cierre temporal de las entidades, establecimientos, empresas o servicios hasta un plazo máximo de cinco años.

3. En los casos determinados en el apartado anterior podrá acordarse la cancelación o suspensión de cualquier tipo de ayuda o subvención de carácter financiero que el particular o entidad infractora hubiera solicitado de la Administración de la Comunidad Foral de Navarra.

\section{DISPOSICION ADICIONAL PRIMERA}

El Gobierno de Navarra podrá actualizar anualmente mediante Decreto Foral las cuantías de las sanciones señaladas en esta Ley Foral, de conformidad con los índices de precios al consumo fijados por el órgano competente en materia de estadística.

\section{DISPOSICION ADICIONAL SEGUNDA}

Las empresas fabricantes de máquinas expendedoras de tabaco dispondrán de dos años, a partir de la aprobación de la presente Ley Foral, para la incorporación de dispositivos tecnológicos a las máquinas automáticas en funcionamiento que permitan controlar la accesibilidad de los compradores de productos de tabaco e impidan el acceso de los menores a esta vía automática.

\section{DISPOSICION TRANSITORIA PRIMERA}

Las limitaciones a la comunicación comercial y promoción del tabaco que afecten a la publicidad contratada con anterioridad a la entrada en vigor de la presente Ley Foral no serán de aplicación hasta transcurridos seis meses desde la publicación de la presente Ley Foral.

\section{DISPOSICION TRANSITORIA SEGUNDA}

Las entidades, establecimientos, empresas y servicios dispondrán de un plazo de seis meses, contados desde la entrada en vigor de esta Ley Foral para adecuarse a sus prescripciones, a partir del cual serán plenamente aplicables. 
Normativa Sanitaria

\section{DISPOSICION TRANSITORIA TERCERA}

La prohibición contemplada en el artículo 21.2 letra I), no será exigible a las empresas afectadas, hasta transcurridos dos años desde la entrada en vigor de la presente Ley Foral, las cuales implantarán progresivamente lo establecido con entendimiento con los trabajadores.

\section{DISPOSICION DEROGATORIA UNICA}

Quedan derogadas cuantas disposiciones de igual o inferior rango se opongan a lo dispuesto en la presente Ley Foral.

\section{DISPOSICION FINAL PRIMERA}

Se autoriza al Gobierno de Navarra a dictar cuantas normas sean precisas para el desarrollo y ejecución de esta Ley Foral.

DISPOSICION FINAL SEGUNDA

La presente Ley Foral entrará en vigor a los veinte días de su publicación en el BOLETIN OFICIAL de Navarra.

Yo, en cumplimiento de lo dispuesto en el artículo 22 de la Ley Orgánica de Reintegración y Amejoramiento del Régimen Foral de Navarra, promulgo, en nombre de S.M. el Rey, esta Ley Foral, ordeno su inmediata publicación en el BOLETIN OFICIAL de Navarra y su remisión al "Boletín Oficial del Estado" y mando a los ciudadanos y a las autoridades que la cumplan y la hagan cumplir.

Pamplona, catorce de febrero de dos mil tres. El Presidente del Gobierno de Navarra, Miguel Sanz Sesma. 